\title{
Correlates of Smoke-Free Policies in Homes and Cars among Hawaii Residents
}

\author{
Lehua B. Choy and Jay E. Maddock \\ University of Hawai ‘i at Mānoa
}

\begin{abstract}
The detrimental health effects of environmental tobacco smoke (ETS) have been well established. Cars and homes are two of the primary places that nonsmokers, particularly children, are exposed to ETS. This study examined the prevalence of smoke-free policies in homes and cars among 4,557 residents of Hawaii using cross-sectional data collected from a random-digit dial telephone survey. Smokers were much less likely than nonsmokers and former smokers to have smoke-free policies. Multivariate analysis of current smokers revealed that significant predictors of banning smoking in the home were: disagreeing that it is okay to smoke indoors, smoking fewer cigarettes per day, and higher confidence in ability to quit smoking. Significant predictors of banning smoking in the car were: disagreeing that it is okay to smoke indoors, smoking fewer cigarettes per day, and having children in the household. This study indicates that changing smokers' attitudes about ETS may be an important component of a comprehensive program to increase smoke-free homes and cars.
\end{abstract}

(C) 2005 Californian Journal of Health Promotion. All rights reserved.

Keywords: environmental tobacco smoke; smoking in home; smoke-free policy; Hawaii

The detrimental health effects of environmental tobacco smoke (ETS), or "secondhand smoke," have been well established. The American Cancer Society (2005) reports that ETS is the third leading preventable cause of death in the U.S.; it kills 38,000 to 65,000 nonsmokers every year. ETS is classified as a Group A carcinogen (U.S. Environmental Protection Agency [EPA], 2005). Exposure to ETS is causally associated with lung cancer, cardiovascular disease, low birthweight, Sudden Infant Death Syndrome, and various respiratory problems, such as asthma and bronchitis (National Cancer Institute, 1999). Children are especially vulnerable to the effects of ETS (EPA, 2005).

The home is one of the primary places that nonsmokers - particularly children - are exposed to ETS (Okah, Choi, Okuyemi, \& Ahluwalia, 2002). It is the most important site for ETS exposure in children, both because they spend much of their time there and because they are often unable to remove themselves from exposure (Ashley \& Ferrence, 1998). Although ETS exposure in homes with children declined significantly nationwide in the 1990s from $36 \%$ to $25 \%$ (Soliman, Pollack, \& Warner, 2004), the home is still a critical place for ETS exposure. In Hawaii, an estimated 11\% $(140,000)$ of residents are at risk for secondhand smoke exposure inside the home, including almost $14 \%(40,200)$ of Hawaii's children (Savail, 2003).

Cars also represent a place where nonsmokers are exposed to ETS. Seventy-seven percent of adults in the U.S. recognize the danger of exposure to ETS in cars (McMillen, Winickoff, Klein, \& Weitzman, 2003). However, much less is known about the effects of ETS exposure in cars. The health consequences are likely serious considering the confined exposure in the car interior (Seo, 2005). The prevalence of exposure to ETS in cars is not well documented. One study of Hawaii youth found that $33 \%$ of middle school and $39 \%$ of high school students were exposed to ETS in a car (Hawaii State Department of Health, 2003).

Smoke-free environments are the most effective method for reducing ETS exposure (CDC, 2005a). Therefore, short of smoking cessation, establishing smoke-free policies (SFPs) in homes and cars may be the best way to reduce health consequences for nonsmoking household 
members (Biener, Cullen, Xiao, \& Hammond, 1997). SFPs can help protect against ETS exposure from both household smokers and visitors, who are an additional source of ETS (Schuster, Franke, \& Pham, 2002). The presence of a SFP indicates that household members acknowledge the dangers of ETS and have taken steps to reduce ETS exposure (Norman, Ribisl, Howard-Pitney, \& Howard, 1999).

The benefits of SFPs in homes appear to extend beyond the reduction of exposure to ETS. Several studies have suggested that SFPs in homes may encourage smoking cessation (Farkas, Gilpin, Distefan, \& Pierce, 1999; Gilpin, White, Farkas, \& Pierce, 1999; Siahpush, Borland, \& Scollo, 2003). One prospective study (Pizacani et al., 2004) found that SFPs in homes may facilitate smoking cessation by increasing quit attempts and prolonging time to relapse among smokers in the preparation stage of change (but not the precontemplation and contemplation stages). Smoke-free homes have also been associated with significantly lower rates of adolescent smoking (Farkas, Gilpin, White, \& Pierce, 2000) and being in earlier stages of smoking uptake among adolescents (Wakefield et al., 2000). Banning smoking in the home may foster antismoking attitudes and norms among adolescents, even if parents smoke (Conley Thompson, Siegel, Winickoff, Biener, \& Rigotti, 2005).

Nationwide, $74 \%$ of adults report a SFP in the home (McMillen et al., 2003). Previous studies have consistently found that current smokers are less likely to have SFPs in their homes than nonsmokers (e.g., Ashley et al., 1998; Pizacani et al., 2003; Walsh, Tzelepis, Paul, \& McKenize, 2002). Approximately $70 \%$ of U.S. adult smokers do not ban smoking in their homes (McMillen et al., 2003). Allowing smoking in homes has been associated with having a high proportion of friends who smoke (King et al., 2005; Norman et al., 1999). On the other hand, not allowing smoking in homes has been associated with the presence of children in the household and being aware of the harm of ETS (Pizacani et al., 2003). Certain demographic characteristics, such as higher education, older age, and higher household income, have also been positively associated with SFPs in homes (Merom \& Rissel, 2001; Norman et al., 1999).

In the few studies which have examined the prevalence of car bans, a range from 38\% (Kegler \& Malcoe, 2002) to 77\% (Walsh et al., 2002) was reported. Again, having a smoke-free car policy has been consistently associated with being a nonsmoker (e.g., King et al., 2005). SFPs in cars have been also associated with having a fewer proportion of friends who smoke and with smoking fewer cigarettes per day (Kegler \& Malcoe, 2002). However, the presence of children in the household has both been associated with a car ban (Norman et al., 1999) and not associated with a car ban (Walsh et al., 2002).

According to data from the 2004 Hawaii State Behavioral Risk Factor Surveillance System (BRFSS), $80 \%$ of Hawaii residents have a SFP in their home (Hawaii State Department of Health, 2004). Similar to national trends, this is a marked increase from $50 \%$ in 1993 and $65 \%$ in 1999 (Levy, Romano, \& Mumford, 2004). Little is known about SFPs in cars in Hawaii. The only published report found that $70 \%$ of Hawaii residents do not allow smoking in their cars (Maddock, 2003). The purpose of this study is to provide further detail on smoke-free home and car policies and their correlates among Hawaii residents. Understanding the correlates of SFPs in homes and cars can improve and help target health promotion interventions designed to address these factors.

\section{Methods}

\section{Data Collection}

Data for this study were collected as part of the on-going evaluation of the Healthy Hawaii Initiative, a statewide social-ecological program designed to increase physical activity, improve nutrition and reduce tobacco use among the residents of Hawaii. A cross-sectional telephone survey was conducted among Hawaii residents aged 18 and older from March through June of 2004. The sample was obtained by random digit dialing procedures $(n=4,557)$ and the survey was conducted using a computer assisted telephone interview (CATI) system. To ensure that a representative sample was collected from 
counties with smaller populations, a roughly equivalent number of respondents were sampled from each of the four counties. The random-digit dialing sampling methods and data collection procedures have been described elsewhere (Maddock, Marshall, Nigg, \& Barnett, 2003)

\section{Measures}

\section{Demographics}

Participants were asked a series of demographic questions, including age, gender, education attained, income level, ethnic identification, and number of household members. The presence of children in the household was assessed by asking how many household members were aged 18 years and older and subtracting that from the total number of people in the household.

\section{SFPs in Homes}

Participants were asked to pick which statement best described the rules about smoking inside their home, not including decks, garages, or lanais (i.e., porches). Having a SFP was defined if the participant said "Smoking is not allowed anywhere inside my home." Participants were categorized as not having a SFP if they chose the statements, "Smoking is allowed in some places or some times," "Smoking is allowed anywhere inside my home," or "There are no rules about smoking inside my home."

\section{SFPs in Cars}

Participants were asked to pick which statement best described how smoking is handled in their cars. A SFP was defined if the participant said, "No one is allowed to smoke in my car." Participants were categorized as not having a SFP if they chose the statements, "Only special guests are allowed to smoke in my car," "People are allowed to smoke in my car if the windows are open," or "There are no rules about smoking inside my car." Participants who said that they did not have a car were treated as missing and excluded from the analysis.

\section{Norms}

\section{Smoking-Related Attitudes and Social}

All participants were asked several questions to assess their attitudes and beliefs about smoking. One question asked if quitting smoking was pleasant or unpleasant on a scale of 1 (unpleasant) to 10 (pleasant). For analysis, the attitude towards quitting was grouped into unpleasant (scores 1-3), neutral (scores 4-7), and pleasant (scores 8-10). The next two items used a 5-point Likert scale (1=strongly disagree, $5=$ strongly agree), asking if (1) it is okay for people to smoke indoors, and if (2) secondhand smoke harms nonsmokers. For analysis, these items were dichotomized into agree or disagree, with the neutral responses being excluded.

\section{Among Current Smokers}

Current smokers were identified if they responded "yes" to the question, "Are you currently a smoker?" Current smokers were asked how many times they tried to quit smoking for at least 24 hours in the past year. Responses were grouped into three categories: 0 times, 1-4 times, and 5 or more times. Stage of change from the Transtheoretical Model was then assessed (Prochaska, DiClemente \& Norcross, 1992). Current smokers who were seriously thinking about quitting within the next 30 days were in the Preparation Stage while those seriously thinking about quitting within the next 6 months were in the Contemplation Stage. Smokers who were not seriously thinking of quitting were categorized in the Precontemplation stage. Smokers were also asked how many cigarettes they smoked per day during a typical week. Responses were grouped into 3 categories: less than 10 per day, 10-19 per day, and 20 or more per day. Finally, selfefficacy was assessed by asking current smokers how confident they were that they could quit smoking on a scale of 1 (not at all confident) to 10 (very confident). For analysis, confidence was grouped into low (scores 1-3), moderate (scores 4-7), and high (scores 8-10).

\section{Data Analysis}

Data were analyzed using SPSS 13.0 for Windows. The overall prevalence of SFPs in homes and cars was weighted by gender and county of residence to the state population. The remaining results are reported unweighted. In the descriptive analysis, chi-square tests were used to test for associations between SFPs and demographic factors and smoking variables. 
Logistic regression was used for the multivariate analysis of SFPs among current smokers only. The full model consisted of all significant variables from the chi-square analyses. For SFPs in homes, the full model consisted of ethnicity, income, age, the presence of children in the home, the belief that secondhand smoke is harmful, the belief that it is okay to smoke indoors, stage of change (precontemplation, contemplation, and preparation), cigarettes smoked per day, and confidence in quitting smoking. For SFPs in cars, the full model consisted of ethnicity, age, the presence of children in the home, the belief that secondhand smoke is harmful, the belief that it is okay to smoke indoors, stage of change (precontemplation, contemplation, and preparation), cigarettes smoked per day, and attitude towards quitting (pleasant/unpleasant).

\section{Results}

Description of Study Participants

The response rate for the study was $41.8 \%$. The average age of participants was 48.4 years (s.d.=16.3 years). Four ethnic groups composed $85 \%$ of the sample: Caucasian $(41.0 \%)$, Native Hawaiian (17.8\%), Japanese (15.4\%), and Filipino (10.9\%). Educational attainment was high, with $29.9 \%$ having a high school degree and $62.6 \%$ having some college/college degree. Less than half $(40.5 \%)$ of respondents reported the presence of children in the household. Almost all participants $(88.9 \%)$ agreed that secondhand smoke harms nonsmokers, plus $82 \%$ said that it is not okay to smoke indoors. The composition by smoking status was $16.1 \%$ current smokers, $3.2 \%$ former smokers who quit within the last 6 months, 30.9\% former smokers who quit more than 6 months ago, and 49.7\% never smokers. Table 1 displays the presence of SFPs in homes and cars by smoking status. Current smokers were the least likely to have SFPs in both their homes and cars.

Table 1

Smoke-free policies (SFPs) in homes and cars by smoking status

\begin{tabular}{|l|c|c|c|c|}
\hline & $\mathbf{n}$ & $\mathbf{\%}$ & SFP in Home (\%) & SFP in Car (\%) \\
\hline TOTAL & 4557 & 100.0 & 79.3 & 81.0 \\
\hline Smoking Status & & & $* * *$ & $* * *$ \\
\hline Current Smoker & 733 & 16.1 & 42.3 & 38.5 \\
\hline Quit $\leq 6$ months & 147 & 3.2 & 72.1 & 70.1 \\
\hline Quit $>$ 6 months & 1407 & 30.9 & 83.1 & 86.9 \\
\hline Never Smoker & 2264 & 49.7 & 89.2 & 92.7 \\
\hline
\end{tabular}

The $\mathrm{p}$ value is associated with a $\chi^{2}$ test. $* * * \mathrm{p}<.001$

\section{SFPs in Homes}

Overall, $79.3 \%$ of respondents had a smoke-free policy in their home, $9.6 \%$ said that smoking is allowed in some places or some times, $8.7 \%$ said that there are no rules about smoking inside the home, and $2.4 \%$ said that smoking is allowed anywhere inside the home. Additionally, 92.5\% of those with a SFP in the home also had a SFP in the car.

\section{SFPs in Cars}

Eighty-one percent of respondents had a smokefree policy in their car, $7.4 \%$ said that people are allowed to smoke in the car if the windows are open, $5.8 \%$ said there are no rules about smoking inside the car, $2.1 \%$ said only special guests are allowed to smoke in the car, and $1.8 \%$ said people are allowed to smoke in the car anytime. Similarly, $90.2 \%$ of those with a SFP in the car also had a SFP in the home. 


\section{Current Smokers Only}

Appendix A shows that among current smokers, the presence of SFPs in homes and cars significantly differed by ethnicity, the presence of children in the household, the belief that secondhand smoke harms nonsmokers, the belief that it is okay to smoke indoors, stage of change, and cigarettes smoked per day. SFPs in homes additionally differed by age, household income, and confidence in quitting. Smokers who were more confident that they could quit were more likely to have smoking ban in their homes, but not necessarily their cars. Further differences in SFPs in cars were found by gender and attitude towards quitting. No differences in SFPs were found by education, county, or quit attempts in the past year.

\section{Multivariate Analysis SFPs in Homes among Current}

\section{Smokers}

Table 2 presents the odds ratios (OR) and associated $95 \%$ confidence intervals (CI) from the final logistic regression model predicting SFPs in homes among current smokers. Significant predictors of banning smoking in the home were disagreeing that it is okay to smoke indoors $(\mathrm{p}<0.001)$, smoking fewer cigarettes per day $(\mathrm{p}<0.01)$, and higher confidence in ability to quit smoking $(\mathrm{p}<0.01)$.

Table 2

Logistic regression model of having a SFP in the home among current smokers

\begin{tabular}{|c|c|c|}
\hline$n=454$ & OR & $95 \% \mathrm{CI}$ \\
\hline \multicolumn{3}{|l|}{ Ethnicity } \\
\hline Caucasian & 1.00 & \\
\hline Hawaiian & 1.07 & $0.62-1.84$ \\
\hline Filipino & 1.55 & $0.70-3.41$ \\
\hline Japanese & 0.86 & $0.40-1.86$ \\
\hline Other & 1.75 & $0.90-3.41$ \\
\hline \multicolumn{3}{|l|}{ Age } \\
\hline 18 to 34 & 1.00 & \\
\hline 35 to 54 & 0.79 & $0.48-1.29$ \\
\hline 55 to 74 & 0.43 & $0.21-0.87$ \\
\hline $75+$ & 1.58 & $0.33-7.56$ \\
\hline \multicolumn{3}{|l|}{ Income } \\
\hline$<\$ 20,000$ & 1.00 & \\
\hline$\$ 20-39,999$ & 1.12 & $0.63-1.97$ \\
\hline$\$ 40-59,999$ & 1.97 & $1.04-3.73$ \\
\hline$\$ 60,000+$ & 1.31 & $0.71-2.45$ \\
\hline \multicolumn{3}{|l|}{ Children in Home } \\
\hline No & 1.00 & \\
\hline Yes & 1.34 & $0.87-2.18$ \\
\hline \multicolumn{3}{|l|}{ Secondhand smoke harms nonsmokers. } \\
\hline Disagree & 1.00 & \\
\hline Agree & 1.32 & $0.69-2.52$ \\
\hline It is okay for people to smoke indoors. & $* * *$ & \\
\hline Disagree & 1.00 & \\
\hline Agree & 0.28 & $0.17-0.45$ \\
\hline \multicolumn{3}{|l|}{ Stage of Change } \\
\hline Preparation & 1.00 & \\
\hline Contemplation & 0.75 & $0.41-1.36$ \\
\hline Precontemplation & 0.63 & $0.35-1.17$ \\
\hline Cigarettes smoked per day & $* *$ & \\
\hline
\end{tabular}




\begin{tabular}{|c|c|c|}
\hline \multicolumn{1}{|c|}{$\mathbf{4 5 4}$} & OR & $\mathbf{9 5 \%}$ CI \\
\hline$<10$ & 1.00 & \\
\hline $10-19$ & 0.84 & $0.50-1.41$ \\
\hline One pack or more & 0.45 & $0.26-0.77$ \\
\hline Confident can quit & $* *$ & \\
\hline Low & 1.00 & \\
\hline Moderate & 2.07 & $1.17-3.66$ \\
\hline High & 2.47 & $1.39-4.40$ \\
\hline$* * 00.01, * * * \mathrm{p}<0.001$ & \multicolumn{2}{|l}{}
\end{tabular}

\section{Smokers}

SFPs in Cars Among Current

Table 3 presents the OR and 95\% CI from the final logistic regression model predicting SFPs in cars among current smokers. Smokers with children living in the home were significantly more likely to have a SFP in their car $(\mathrm{p}<0.01)$.
Compared to smokers who disagreed that it is okay to smoke indoors, smokers who agreed that it is okay to smoke indoors were half as likely to have a SFP in the car $(\mathrm{OR}=0.52, \mathrm{CI}=0.34-0.78)$. Also, smokers who smoked more cigarettes per day were significantly less likely to have a SFP in their cars $(p<0.001)$.

Table 3

Logistic regression model of having a SFP in the car among current smokers

\begin{tabular}{|c|c|c|}
\hline \multicolumn{1}{|c|}{$\mathbf{n = 5 6 0}$} & $\mathbf{O R}$ & $\mathbf{9 5 \%}$ CI \\
\hline Ethnicity & & \\
\hline Caucasian & 1.00 & \\
\hline Hawaiian & 1.39 & $0.87-2.21$ \\
\hline Filipino & 1.22 & $0.63-2.36$ \\
\hline Japanese & 1.77 & $0.92-3.39$ \\
\hline Other & 0.88 & $0.48-1.59$ \\
\hline Gender & & \\
\hline Male & 1.00 & \\
\hline Female & 1.12 & $0.77-1.63$ \\
\hline Children in Home & $* *$ & \\
\hline No & 1.00 & \\
\hline Yes & 1.72 & $1.17-2.52$ \\
\hline Secondhand smoke harms nonsmokers. & & \\
\hline Disagree & 1.00 & \\
\hline Agree & 1.35 & $0.80-2.29$ \\
\hline It is okay for people to smoke indoors. & $* *$ & \\
\hline Disagree & 1.00 & \\
\hline Agree & 0.52 & $0.34-0.78$ \\
\hline Stage of Change & & \\
\hline Preparation & 1.00 & \\
\hline Contemplation & 0.59 & $0.36-0.99$ \\
\hline Precontemplation & 0.67 & $0.39-1.13$ \\
\hline Cigarettes smoked per day & $* * *$ & \\
\hline$<10$ & 1.00 & \\
\hline 10-19 & 0.52 & $0.33-0.83$ \\
\hline & & \\
\hline & & \\
\hline & &
\end{tabular}




\begin{tabular}{|c|c|c|}
\hline $\mathbf{n = 5 6 0}$ & OR & $\mathbf{9 5 \%}$ CI \\
\hline One pack or more & 0.38 & $0.24-0.60$ \\
\hline Attitude towards quitting & & \\
\hline Unpleasant & 1.00 & \\
\hline Neutral & 1.36 & $0.86-2.13$ \\
\hline Pleasant & 1.22 & $0.78-1.90$ \\
\hline${ }^{* *} \mathrm{p}<0.01,{ }^{* * *} \mathrm{p}<0.001$ & \multicolumn{3}{|l}{}
\end{tabular}

\section{Discussion}

This study found that $79.3 \%$ of Hawaii residents have a SFP policy in their home, similar to the prevalence reported by the Hawaii State BRFSS. Furthermore, this study was among the first to report on SFPs in the cars of Hawaii residents, finding that $81.0 \%$ do not allow smoking in their cars. Current smokers were of particular interest because they are the least likely to have SFPs in their homes and cars, yet would be the most likely to expose family members to ETS. In the univariate analysis, correlates of having SFPs somewhat varied for homes and cars. The correlates in common were ethnicity, the presence of children in the home, the belief that secondhand smoke harms nonsmokers, the belief that it is okay to smoke indoors, stage of change, and cigarettes smoked per day.

In the multiple logistic regression analyses of current smokers, statistically significant predictors of SFPs in the home were disagreeing that it is okay for people to smoke indoors, smoking fewer cigarettes per day, and having more confidence in ability to quit. Similarly, statistically significant predictors of SFPs in the car were disagreeing that it is okay for people to smoke indoors, smoking fewer cigarettes per day, and the presence of children in the home. Taken together, these results suggest that smokers who have SFPs in their homes and cars differ in their smoking-related attitudes and behaviors from smokers without SFPs. Smokers with SFPs are lighter smokers, have higher selfefficacy in their ability to quit, and are more likely to be in the preparation stage of change. Additionally, these smokers have more negative attitudes towards ETS.

An encouraging finding is that the presence of children in the household was linked to a greater likelihood of having SFPs in homes and cars. However, a substantial proportion of children living with current smokers are not protected by SFPs. Approximately half of current smokers with children in their household do not ban smoking in their homes $(47.2 \%)$ or cars $(52.8 \%)$. This highlights the need to emphasize the benefits of instituting personal SFPs in homes and cars among current smokers, particularly those living with children. Even if smokers are not willing to quit, choosing to smoke outdoors or before getting in the car are basic steps that can be taken to minimize the harm to their family members.

\section{Limitations}

First of all, the low response rate may have affected the results. Caution should be used in generalizing these findings to the entire state of Hawaii. Secondly, the data from this study are cross-sectional, so the nature of the relationships cannot be determined. For example, the association between smoking fewer cigarettes per day and having a SFP may be that smokers with SFPs are less addicted, which makes it easier for them to have smoke-free homes and cars. On the other hand, a SFP may weaken the power of various environmental cues to smoke or may disrupt behavior by causing the smoker to delay cigarettes (Farkas et al., 1999). To address this problem, more longitudinal studies should be conducted among current smokers with and without SFPs. These studies may provide valuable evidence that SFPs help smokers to quit.

Another limitation with this study is that it is based on self-report. Having a SFP does not necessarily mean that it is enforced. With increased awareness of ETS harm, saying one has a SFP may be socially desirable to smokers. 
One study found that SFPs in the home were associated with lower levels of ETS exposure through biochemical validation (Berman et al., 2003). Yet, another study found that home smoking restrictions did not eliminate ETS exposure in children living with smokers (Hopper \& Craig, 2000). Additionally, Mumford and colleagues (2004) found discrepancies among household members' reports of home smoking bans. Multimember households with current smokers were less likely to consistently report the presence of SFPs, which brings into question the validity of individual reports.

\section{Implications for Health Education}

Adopting SFPs depends primarily on believing in the health consequences of ETS exposure and making the effort to establish and enforce social norms promoting smoke-free environments (King et al., 2005). Given this, one important correlate to emerge from this study is the attitude towards smoking indoors. Smokers who did not think that it was acceptable to smoke indoors were significantly more likely to have SFPs in their homes and cars. Modifying smokers' attitudes towards ETS may help to create more SFPs in the homes and cars of Hawaii residents. Educating smokers about the negative effects of ETS and addressing misconceptions about the acceptability of smoking indoors should be integral components of an educational campaign. For example, smokers may think it is okay to smoke in the home if the windows are open. However, homes do not have adequate ventilation systems to eliminate secondhand smoke (CDC, 2005b). Using a framework based on social cognitive theory may be a promising approach to use in SFP interventions (Gehrman \& Hovell, 2003).

In addressing potential interventions, there are several cultural factors to consider for the Asian American residents of Hawaii. Generally, the desire to be sociable and hospitable has been documented to be a barrier to smoke-free homes and thus should be addressed (Jochelson, Hua, \& Rissel, 2003). Also, subgroups of Asian Americans are less likely to have a SFP in the home and could benefit from interventions. Ma and colleagues (2004) found that less acculturated Asian Americans and certain ethnic subgroups (Vietnamese, Cambodians, Koreans) had higher rates of smoking in the home. Emphasizing the adverse health effects of ETS on nonsmokers and children may help to promote SFPs since Asian American cultures tend to place family needs before individual ones (Ma, Tan, Fang, Toubbeh, \& Shive, 2005). By encouraging smokers to establish SFPs in their homes and cars, nonsmokers-especially children - are protected from ETS. Smokers may also benefit from SFPs by improving their prospects for cessation.

\section{References}

American Cancer Society. (2005). The facts about secondhand smoke. Retrieved April 18, 2005, from http://www.cancer.org/docroot/COM/content/div TX/COM 11_2x The Facts about Secondha nd_Smoke.asp?sitearea $=\mathrm{COM}$

Ashley, M. J., Cohen, J., Ferrence, R., Bull, S., Bondy, S., Poland, B., \& Pederson, L. (1998). Smoking in the home: Changing attitudes and current practices. American Journal of Public Health, 88, 797800 .

Ashley, M. J., \& Ferrence, R. (1998). Reducing children's exposure to environmental tobacco smoke in homes: Issues and strategies. Tobacco Control, 7, 61-65.

Berman, B. A., Wong, G. C., Bastani, R., Hoang, T., Jones, C., Goldstein, D. R., et al. (2003). Household smoking behavior and ETS exposure among children with asthma in low-income, minority households. Addictive Behaviors, 28, 111-128.

Biener, L., Cullen, D., Di, Z. X., \& Hammond, S. K. (1997). Household smoking restrictions and adolescents' exposure to environmental tobacco smoke. Preventive Medicine, 26, 358-363.

Centers for Disease Control and Prevention. (2005a). Exposure to environmental tobacco smoke (Fact Sheet). Retrieved July 25, 2005, from http://www.cdc.gov/tobacco/research_data/environmental/factsheet_ets.htm 
Centers for Disease Control and Prevention. (2005b). Secondhand smoke in your home. Retrieved July 25, 2005, from http://www.cdc.gov/tobacco/research data/environmental/etsfact3.htm

Conley Thomson, C., Siegel, M., Winickoff, J., Biener, L., \& Rigotti, N. A. (2005). Household smoking bans and adolescents' perceived prevalence of smoking and social acceptability of smoking. Preventive Medicine, 41, 349-356.

Farkas, A. J., Gilpin, E. A., Distefan, J. M., \& Pierce, J. P. (1999). The effects of household and workplace smoking restrictions on quitting behaviours. Tobacco Control, 8, 261-265.

Farkas, A. J., Gilpin, E. A., White, M. A., \& Pierce, J. P. (2000). Association between household and workplace smoking restrictions and adolescent smoking. The Journal of the American Medical Association, 284, 717-722.

Gehrman, C. A., \& Hovell, M. F. (2003). Protecting children from environmental tobacco (ETS) exposure: A critical review. Nicotine \& Tobacco Research, 5, 289-301.

Gilpin, E. A., White, M. M., Farkas, A. J., \& Pierce, J. P. (1999). Home smoking restrictions: Which smokers have them and how they are associated with smoking behavior. Nicotine \& Tobacco Research, 1, 153-162.

Hawaii State Department of Health. (2003). Hawaii youth tobacco survey: Selected indicators for middle school and high school, 2000 and 2003. Retrieved July 26, 2005, from http://www.hawaii.gov/health/statistics/other-reports/2003-yts-highlights.pdf

Hawaii State Department of Health. (2004). Hawaii behavioral risk factor surveillance system. Retrieved July 26, 2005, from http://www.hawaii.gov/health/statistics/brfss/brfss2004/2004/demo04/s1.html

Hopper, J. A., \& Craig, K. A. (2000). Environmental tobacco smoke exposure among urban children. Pediatrics, 106(4), E47. Retrieved June 6, 2005, from http://www.pediatrics.org/cgi/content/full/106/4/e47

Jochelson, T., Hua, M., \& Rissel, C. (2003). Knowledge, attitudes and behaviours of caregivers regarding children's exposure to environmental tobacco smoke among Arabic and Vietnamese-speaking communities in Sydney, Australia. Ethnicity \& Health, 8, 339-351.

Kegler, M. C., \& Malcoe, L. H. (2002). Smoking restrictions in the home and car among rural Native American and white families with young children. Preventive Medicine, 35, 334-342.

King, G., Mallett, R., Kozlowski, L., Bendel, R. B., \& Nahata, S. (2005). Personal space smoking restrictions among African Americans. American Journal of Preventive Medicine, 28, 33-40.

Levy, D. T., Romano, E., \& Mumford, E. A. (2004). Recent trends in home and work smoking bans. Tobacco Control, 12, 258-263.

Ma, G. X., Shive, S. E., Tan, Y., \& Feeley, R. M. (2004). The impact of acculturation on smoking in Asian American homes. Journal of Health Care for the Poor and Underserved, 15, 267-280.

Ma, G. X., Tan, Y., Fang, C. Y., Toubbeh, J. I., \& Shive, S. E. (2005). Knowledge, attitudes and behavior regarding secondhand smoke among Asian Americans. Preventive Medicine, 41, 446-453.

Maddock, J.E. (2003). Smoking and tobacco use in Hawai'i: Facts, figures, and trends. Hawaii State Department of Health, Tobacco Prevention and Education Program. Retrieved September 26, 2005, from http://www.hawaii.gov/health/healthy-lifestyles/tobacco/resources/general/trends.pdf

Maddock, J. E., Marshall, C. S., Nigg, C. R., \& Barnett, J. D. (2003). Development and first year results of a psychosocial surveillance system for chronic disease related health behaviors. Californian Journal of Health Promotion, 1, 54-64. Retrieved August 1, 2005, from http://www.csuchico.edu/cjhp/1/hawaii/index.htm

McMillen, R. C., Winickoff, J. P., Klein, J. D., \& Weitzman, M. (2003). US adult attitudes and practices regarding smoking restrictions and child exposure to environmental tobacco smoke: Changes in the social climate from 2000-2001. Pediatrics, 112(1), e55-e60. Retrieved June 6, 2005, from http://www.pediatrics.org/cgi/content/full/112/1/e55

Merom, D., \& Rissel. C. (2001). Factors associated with smoke-free homes in NSW: Results from the 1998 NSW Health Survey. Australian and New Zealand Journal of Public Health, 25, 339-345.

Mumford, E. A., Levy, D. T., \& Romano, E. O. (2004). Home smoking restrictions: Problems in classification. American Journal of Preventive Medicine, 27, 126-131. 
National Cancer Institute. (1999). Health effects of environmental tobacco smoke: The report of the California Environmental Protection Agency. Smoking and Tobacco Control Monograph 10. Retrieved July 21, 2005, from http://cancercontrol.cancer.gov/tcrb/monographs/10/

Norman, G. J., Ribisl, K. M., Howard-Pitney, B., \& Howard, K. A. (1999). Smoking ban in the home and car: Do those who really need them have them? Preventive Medicine, 29, 582-589.

Okah, F. A., Choi, W. S., Okuyemi, K., \& Ahluwalia, J. S. (2002). Effect of children on home smoking restriction by inner-city smokers. Pediatrics, 109, 244-249.

Pizacani, B. A., Martin, D. P., Stark, M. J., Koepsell, T. D., Thompson, B., \& Diehr, P. (2003). Household smoking bans: Which households have them and do they work? Preventive Medicine, 36, 99-107.

Pizacani, B. A., Martin, D. P., Stark, M. J., Koepsell, T. D., Thompson, B., \& Diehr, P. (2004). A prospective study of household smoking bans and subsequent cessation of related behavior: The role of stage of change. Tobacco Control, 13, 23-28.

Prochaska, J. O., DiClemente, C. C. \& Norcross, J. C. (1992). In search of how people change: Applications to addictive behaviors. American Psychologist, 47, 1102-1114.

Savail, F. R. (2003). Exposure to secondhand cigarette smoke at home. Retrieved July 26, 2005, from http://www.state.hi.us/health/statistics/brfss/reports/2ndhandsmoke02.pdf

Schuster, M. A., Franke, T., \& Pham, C. B. (2002). Smoking patterns of household members and visitors in homes with children in the United States. Archives of Pediatrics and Adolescent Medicine, $156,1094-1100$.

Seo, D. (2005). Correlates of attitudes toward a smoking ban in vehicles. Journal of Public Health Management and Practice, 11, 346-350.

Siahpush, M., Borland, R., \& Scollo, M. (2003). Factors associated with smoking cessation in a national sample of Australians. Nicotine \& Tobacco Research, 5, 597-602.

Soliman, S., Pollack, H. A., \& Warner, K. E. (2004). Decrease in the prevalence of environmental tobacco smoke exposure in the home during the 1990s in families with children. American Journal of Public Health, 94, 314-320.

U. S. Environmental Protection Agency. (2005). Health effects of exposure to secondhand smoke. Retrieved September 30, 2005, from http://www.epa.gov/smokefree/healtheffects.html

Wakefield, M. A., Chaloupka, F. J., Kaufman, N. J., Orleans, C. T., Barker, D. C., \& Ruel, E. E. (2000). Effect of restrictions on smoking at home, at school, and in public places on teenage smoking: Cross sectional study. British Medical Journal, 321, 333-337.

Walsh, R. A., Tzelepis, F., Paul, C. L., \& McKenzie, J. (2002). Environmental tobacco smoke in homes, motor vehicles and licensed premises: Community attitudes and practices. Australian and New Zealand Journal of Public Health, 26, 536-542.

\section{Acknowledgements}

Funding for this study provided by the Hawai'i State Department of Health, Tobacco Settlement Special Fund, as part of the Healthy Hawai' $i$ Initiative. Thank you to Lila Johnson at the State Tobacco Prevention \& Education Program for providing reference materials. The authors would also like to thank the members of the Healthy Hawai'i Initiative Evaluation Team. 


\author{
$\underline{\text { Author Information }}$ \\ Lehua B. Choy \\ University of Hawai'i at Manoa \\ Department of Public Health Sciences \\ E-Mail: lehuac@hawaii.edu \\ Jay E. Maddock, Ph.D* \\ Graduate Chair and Associate Professor \\ Department of Public Health Sciences \\ University of Hawaii at Manoa \\ 1960 East-West Rd. \\ Honolulu, HI 96822 \\ Ph.: 808-956-5779 \\ Fax: 808-956-6041 \\ E-Mail: jmaddock@hawaii.edu \\ * corresponding author
}




\section{Appendix A}

Smoke-free policies (SFPs) in homes and cars among current smokers only

\begin{tabular}{|c|c|c|c|c|}
\hline & $\mathbf{N}$ & $\%$ & SFP in home $(\%)$ & SFP in car (\%) \\
\hline TOTAL & 733 & 100.0 & 42.3 & 37.2 \\
\hline Ethnicity & & & $*$ & $*$ \\
\hline Caucasian & 309 & 42.4 & 37.2 & 33.6 \\
\hline Hawaiian & 176 & 24.2 & 45.5 & 45.9 \\
\hline Filipino & 69 & 9.5 & 50.7 & 45.6 \\
\hline Japanese & 73 & 10.0 & 37.0 & 45.7 \\
\hline Other & 101 & 13.9 & 50.5 & 30.9 \\
\hline Age & & & $* *$ & \\
\hline 18 to 34 & 220 & 30.7 & 51.8 & 41.5 \\
\hline 35 to 54 & 335 & 46.7 & 41.2 & 38.2 \\
\hline 55 to 74 & 145 & 20.2 & 32.4 & 37.6 \\
\hline $75+$ & 17 & 2.4 & 29.4 & 33.3 \\
\hline Gender & & & & $*$ \\
\hline Male & 352 & 48.0 & 41.5 & 33.6 \\
\hline Female & 381 & 52.0 & 43.0 & 43.0 \\
\hline \multicolumn{5}{|l|}{ Education } \\
\hline$<$ High School & 80 & 10.9 & 41.3 & 39.0 \\
\hline High School Degree & 286 & 39.0 & 39.9 & 36.4 \\
\hline College $1-3$ years & 221 & 30.2 & 41.2 & 37.7 \\
\hline College $4+$ years & 146 & 19.9 & 49.3 & 43.4 \\
\hline Household Income & & & $*$ & \\
\hline$<\$ 20,000$ & 146 & 25.3 & 37.7 & 42.6 \\
\hline$\$ 20-39,999$ & 178 & 30.9 & 36.0 & 31.4 \\
\hline$\$ 40-59,999$ & 121 & 21.0 & 49.6 & 36.8 \\
\hline$\$ 60,000+$ & 131 & 22.7 & 48.1 & 44.6 \\
\hline \multicolumn{5}{|l|}{ County } \\
\hline Maui & 216 & 29.5 & 44.0 & 36.2 \\
\hline Kauai & 160 & 21.8 & 41.9 & 33.5 \\
\hline Hawaii & 183 & 25.0 & 39.9 & 39.7 \\
\hline Honolulu & 174 & 23.7 & 43.1 & 44.8 \\
\hline Children in Home & & & $* * *$ & $* * *$ \\
\hline No & 426 & 58.1 & 34.7 & 32.2 \\
\hline Yes & 307 & 41.9 & 52.8 & 47.2 \\
\hline $\begin{array}{l}\text { Secondhand smoke harms } \\
\text { nonsmokers. }\end{array}$ & & & $*$ & * \\
\hline Disagree & 103 & 15.0 & 34.0 & 29.1 \\
\hline Agree & 585 & 85.0 & 44.6 & 40.1 \\
\hline $\begin{array}{l}\text { It is okay for people to smoke } \\
\text { indoors. }\end{array}$ & & & $* * *$ & $* * *$ \\
\hline Disagree & 431 & 64.6 & 55.9 & 46.6 \\
\hline Agree & 236 & 35.4 & 22.0 & 25.2 \\
\hline Stage of Change & & & $* * *$ & $*$ \\
\hline Precontemplation & 117 & 16.0 & 34.8 & 35.5 \\
\hline Contemplation & 271 & 37.0 & 45.8 & 37.7 \\
\hline
\end{tabular}




\begin{tabular}{|c|c|c|c|c|}
\hline & $\mathbf{N}$ & $\mathbf{\%}$ & SFP in home (\%) & SFP in car (\%) \\
\hline Preparation & 302 & 41.2 & 55.6 & 50.9 \\
\hline Cigarettes smoked per day & & & $* * *$ & $* * *$ \\
\hline$<10$ & 210 & 28.6 & 54.3 & 52.5 \\
\hline $10-19$ & 233 & 31.8 & 45.9 & 36.6 \\
\hline One pack or more & 290 & 39.6 & 30.7 & 30.0 \\
\hline Quit attempt in past year & & & & 36.4 \\
\hline None & 251 & 34.2 & 40.6 & 35.6 \\
\hline $1-4$ & 275 & 37.5 & 39.3 & 45.0 \\
\hline 5 or more & 207 & 28.2 & 48.3 & 34.3 \\
\hline Confident can quit & & & $* * *$ & 37.2 \\
\hline Low & 183 & 25.7 & 29.5 & $* 4.2$ \\
\hline Moderate & 284 & 39.9 & 42.6 & 32.2 \\
\hline High & 244 & 34.3 & 51.6 & 45.2 \\
\hline Attitude towards quitting & & & & 39.8 \\
\hline Unpleasant & 268 & 37.7 & 40.3 & 42.3 \\
\hline Neutral & 215 & 30.3 & 45.8 & \\
\hline Pleasant & 227 & 32.0 & & \\
\hline
\end{tabular}

The $\mathrm{p}$ value is associated with a $\chi^{2}$ test. ${ }^{*} \mathrm{p}<.05,{ }^{* *} \mathrm{p}<.01,{ }^{* * *} \mathrm{p}<.001$ 